\title{
Normal Pole Formation During Total Inhibition of Wall Synthesis of Bacillus subtilis
}

\author{
By ARTHUR L. KOCH ${ }^{1 *}$ AND IAN D. J. BURDETT ${ }^{2}$ \\ 'Department of Biology, Indiana University, Bloomington, Indiana 47405, USA \\ ${ }^{2}$ National Institute for Medical Research, The Ridgeway, Mill Hill, London NW7 IAA, UK
}

(Received 13 January 1986; revised 20 June 1986)

\begin{abstract}
Previous work has shown that the side wall of a Gram-positive rod is initially laid down as a compact layer inside the older wall. It is then stretched as it comes to bear tension due to the osmotic pressure inside the cell. If the polar wall is likewise capable of a degree of expansion, then no new murein need be added while the planar cross-wall splits and converts into two poles. In Bacillus subtilis mutant strain FJ6, which is deficient in autolytic enzymes, pole formation can be caused by addition of exogenous muramidase $\left(10 \mu \mathrm{g}\right.$ hen egg white lysozyme $\mathrm{ml}^{-1}$ for $10 \mathrm{~min}$ at $35^{\circ} \mathrm{C}$ ). This strain grows as long filaments with many completed cross-walls, but enzymic treatment caused the formation of many new poles of normal morphology as judged by thin section electron microscopy. Fully separated poles of normal appearance were also found when more than 100 times the MIC $\left(1 \mu \mathrm{g} \mathrm{ml}^{-1}\right)$ of vancomycin was added to block wall growth totally and rapidly $10 \mathrm{~min}$ before the addition of lysozyme. We conclude, therefore, that no new murein is needed in the conversion of the flat septum into poles and that the unstressed cross-wall is capable of the necessary expansion.
\end{abstract}

\section{INTRODUCTION}

The surface stress theory (Koch, 1983, 1984, 1985; Burdett \& Koch, 1984) acknowledges that murein can only be incorporated into the bacterial wall in a stress-free condition. For Grampositive rods this implies that the septal cross-wall is stress-free before splitting takes place. This raises a question: does the peptidoglycan of the completed septum have sufficient elasticity to expand enough to cover the larger area of the mature pole? The stress, due to hydrostatic pressure, only comes to act and cause strain as the septum is split. Because of the relative conformation of newly incorporated versus fully stressed peptidoglycan residues, it is possible that no additional peptidoglycan need be added while the expansion of the pole takes place. In this paper, we tested this hypothesis through electron microscopic studies of pole development in which a filamentous mutant strain of Bacillus subtilis, FJ6, was treated with hen egg white lysozyme. Using a short exposure to the enzyme to reduce the possibility of additional murein deposition, we observed the formation of poles that appeared to be normal and were attributable to the exogenous muramidase. This conclusion was strengthened by the observation that normal poles developed even in the presence of a high concentration of vancomycin, which inhibits wall synthesis (see Rogers et al., 1980). It is shown, therefore, that conformational changes alone are sufficient to expand the bisected, completed planar septum into two new cup-shaped poles.

\section{METHODS}

Bacterial strain and growth conditions. B. subtilis FJ6, an autolysin-deficient strain (Fein \& Rogers, 1976), was cultured in LB broth (Miller, 1972) at $35^{\circ} \mathrm{C}$ with shaking; these conditions are parallel to those used by Burdett (1980) in studies of the parental strain B. subtilis MB21. Strain FJ6 is deficient in both of the known autolysins ( $N$ acetylmuramyl-L-alanine amidase and endo- $\beta$ - $N$-acetylglucosaminidase; Rogers, 1979) and grows as long filaments that form tight, sometimes helical, bundles. Because growth is no doubt unbalanced in the centre of such fibers, special care was taken to vortex the culture vigorously at $30 \mathrm{~min}$ intervals over the course of several hours 
before the beginning of the experiments. This treatment produced filaments 50-200 cell lengths long which were not aggregated into large clumps.

Addition of vancomycin and lysozyme. Experiments were conducted by adding vancomycin (Sigma) to a final concentration of $100 \mu \mathrm{g} \mathrm{ml}^{-1}$, subdividing the culture, adding lysozyme (Worthington) at various concentrations to the aliquot, shaking the test tubes by hand, and adding, after exactly 10 min of treatment at $35^{\circ} \mathrm{C}$, the required volume of fixative (see below). Vancomycin and lysozyme were prepared in distilled water.

Electron microscopy. Sufficient fixative was used such that the fixative concentration in the growth medium was $2 \%(\mathrm{v} / \mathrm{v})$ glutaraldehyde, $1 \%(\mathrm{v} / \mathrm{v})$ paraformaldehyde, $80 \mathrm{mM}-\mathrm{KCl}$ and $10 \mathrm{mM}$-magnesium acetate (Burdett \& Higgins, 1978; Burdett, 1980). Samples were fixed for $2 \mathrm{~h}$, filtered onto membrane filters (type HA, $0.45 \mu \mathrm{m}$ pore size, $10 \mathrm{~mm}$ diameter, Millipore) and washed with $0.05 \mathrm{M}$-cacodylate buffer, $\mathrm{pH} 6 \cdot 2$, containing $80 \mathrm{mM}-\mathrm{KCl}$ and 10 $\mathrm{mM}$-magnesium acetate. Filtration tended to settle the cells lengthwise on the surface of the filter thus increasing the potential yield of longitudinally sectioned organisms. To preserve this orientation, a drop of $2 \%(\mathrm{w} / \mathrm{v})$ molten agar was placed onto the filter and left to harden before postfixation in $1 \%(\mathrm{w} / \mathrm{v}) \mathrm{OsO}_{4}$ and subsequent treatment as described previously (Burdett \& Higgins, 1978; Burdett, 1980).

Light microscopy. Micrographs were recorded on $35 \mathrm{~mm}$ Pan F film, using a Zeiss photomicroscope III.

Measurements. Wall thickness measurements were made from electron microscope negatives or directly from photographic prints, using an eye-piece graticule. At least 10 measurements were made. Cell length determinations were made from photographic prints using a graphics tablet interfaced to an Apple II microcomputer.

\section{RESULTS}

\section{Morphometric measurements of normally growing FJ6 cells}

A simulated sequence of cross-wall formation in strain FJ6 is shown in Fig. 1. The cross-walls were mostly complete and only a small percentage showed evidence of splitting into two poles. The mean thickness of the cross-wall (mean \pm SD) was $79 \pm 12 \mathrm{~nm}$, whereas that of the parental strain MB21 was $56 \pm 5 \mathrm{~nm}$. This difference in mean cross-wall thickness may be due to the presence of irregular thickened patches of wall along the septum of strain FJ6. Separation of the cross-wall into two poles in MB21 was similar to that described in B. subtilis 168/s (Burdett \& Higgins, 1978). Although the surface of the peripheral wall along the cylindrical portion of the cell was roughened in strain MB21, it lacked the conspicuous fringe visible in sections of FJ6 (Fig. 1). Peripheral wall thickness in strain MB21 was $37 \pm 6 \mathrm{~nm}$; in strain FJ6 the total wall thickness, including the fringe, was $53 \pm 8 \mathrm{~nm}$ (Table 1). If the fringe was excluded, so that only the tribanded (dark-light-dark) portion was measured, the wall thickness of strain FJ6 was $38 \pm$ $2 \mathrm{~nm}$.

Examination of low magnification micrographs showed that the normal pole-to-pole distance of strain MB21 was approximately $2.6 \pm 0.6 \mu \mathrm{m}$ (Table 1 ). The mean length of the comparable cellular unit, between the cross-walls of FJ6, was $2.4 \pm 0.6 \mu \mathrm{m}$. Consequently, the septation site appeared to be quite normally placed in the autolysin-deficient strain.

\section{Effect of lysozyme concentration}

All experiments were designed to keep the time of exposure to lysozyme brief (10 min). Of course, too little lysozyme caused no observable changes, but too much $\left(100 \mu \mathrm{g} \mathrm{ml}^{-1}\right)$ caused lysis, and still higher concentrations $\left(1 \mathrm{mg} \mathrm{ml}^{-1}\right)$ resulted in objects that appeared to be of the same size and shape as the original bacteria. We believe that these structures were probably artifacts resulting from the formation of a precipitate between the large excess of the basic lysozyme protein in the medium and the bulk of the proteins of the cell, which mostly have an acidic iso-electric point.

\section{Formation of poles with lysozyme from previously completed walls}

For our purposes $10 \mu \mathrm{g}$ lysozyme $\mathrm{ml}^{-1}$ appeared to be optimal since splitting of the cross-walls could be observed and the residual filaments were much shorter $(64 \pm 48 \mu \mathrm{m})$ than in the absence of enzyme $(598 \pm 319 \mu \mathrm{m}$; see Table 1). Note that the distribution of sizes was very broad. Because of the length of original filaments most of the completed poles observed after enzyme treatment must have resulted from the action of lysozyme and not from the effect of the residual level of either the glucosaminidase or the amidase present in FJ6. Examples of the short 

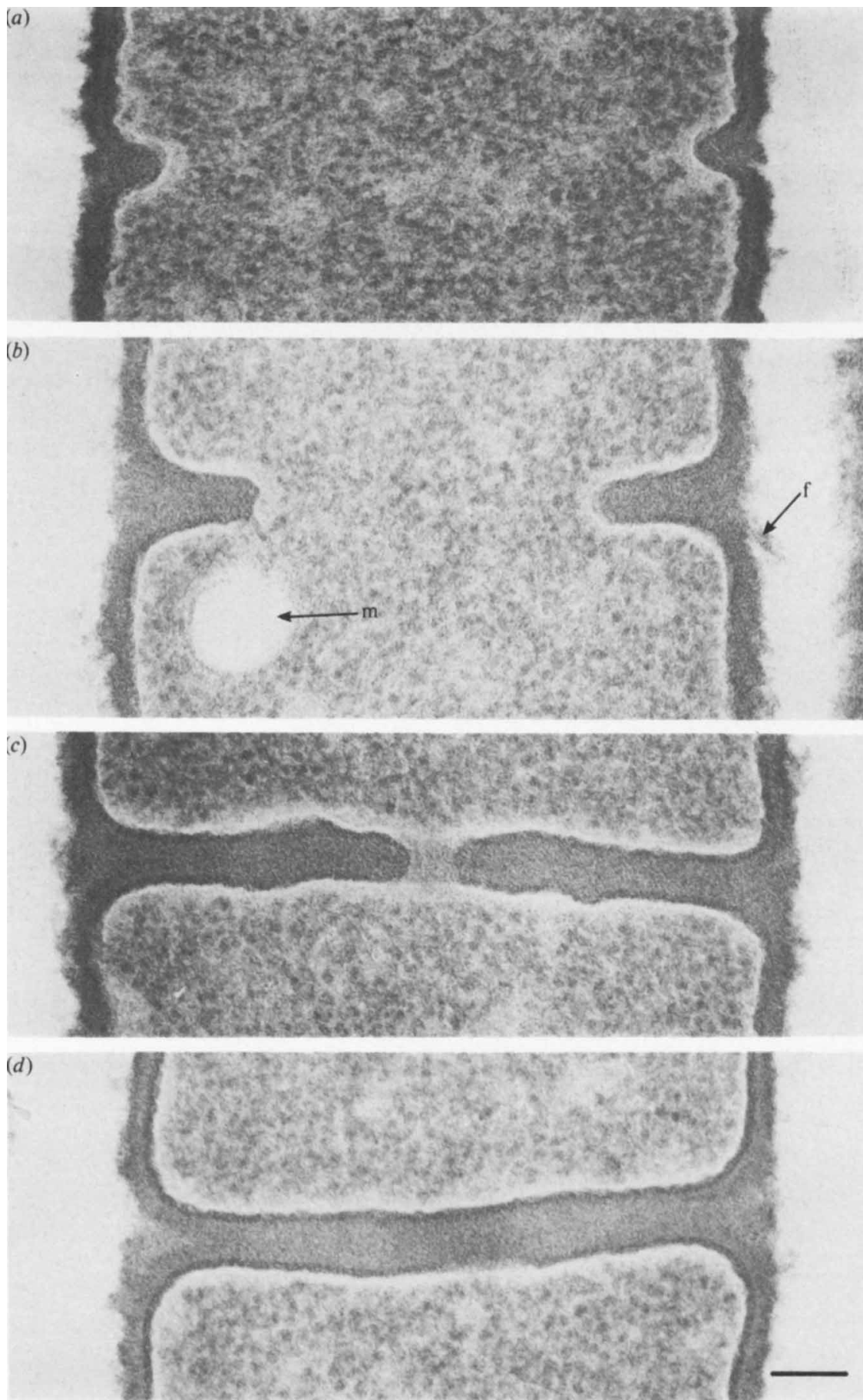

Fig. 1. Simulated sequence of cross-wall formation in B. subtilis FJ6 grown in LB medium at $35^{\circ} \mathrm{C}$, based on electron micrographs of longitudinally sectioned cells. Initiation $(a)$ and further ingrowth of the cross-wall $(b-d)$ is shown. Note that the completed cross-wall $(d)$ only rarely (or slowly) splits. $\mathrm{m}$, Mesosome; f, fringe of wall material covering the cylindrical wall. Bar. $0 \cdot 1 \mu \mathrm{m}$. 


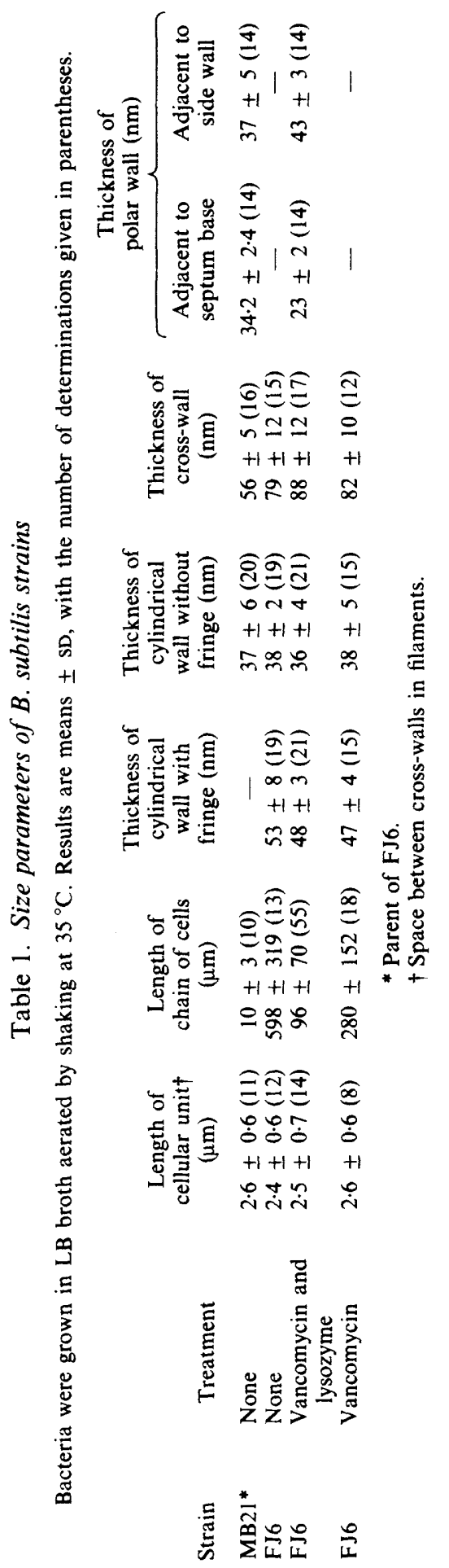



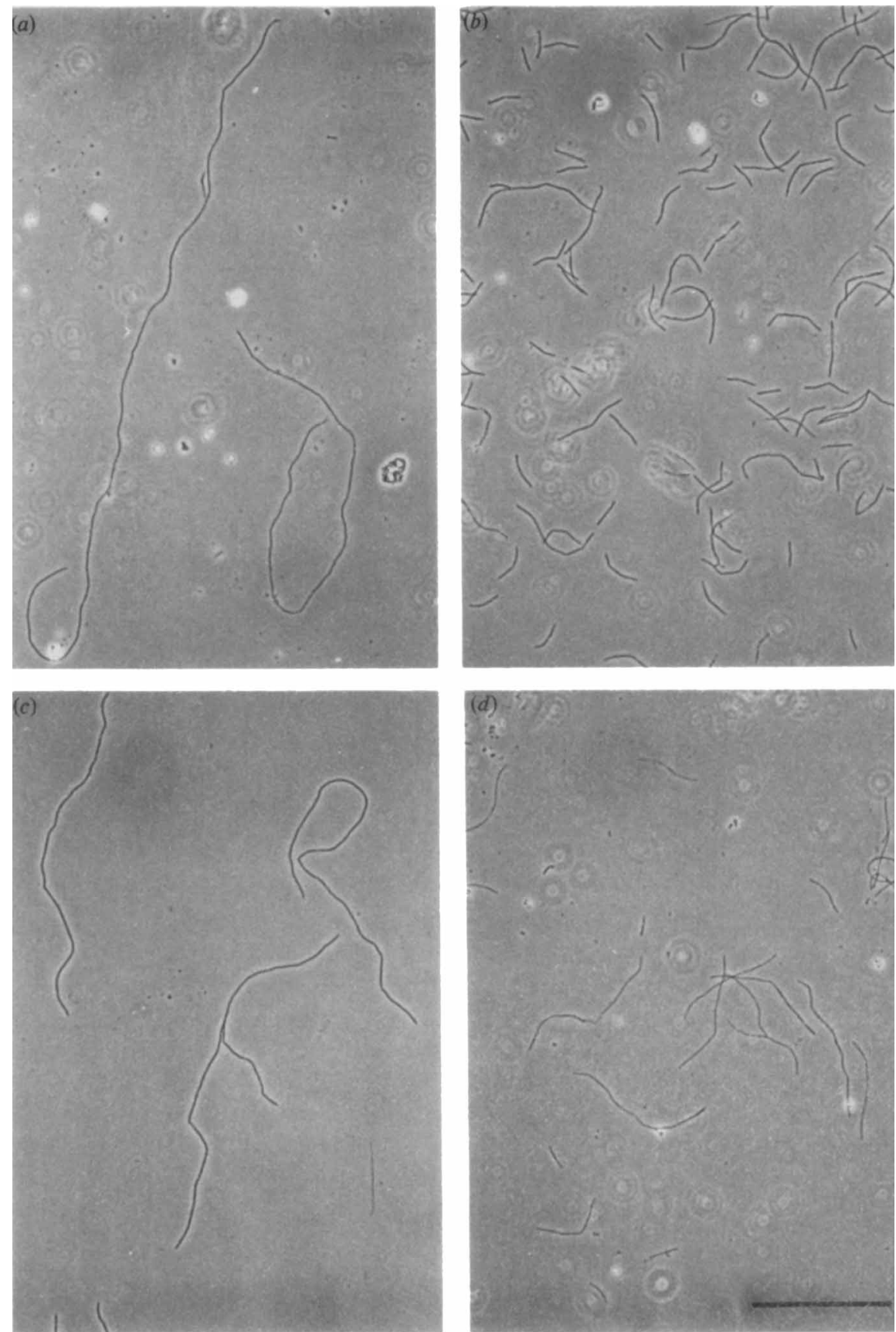

Fig. 2. Phase-contrast micrographs of $B$. subtilis FJ6 after (a) no addition (control), or addition of (b) lysozyme $\left(10 \mu \mathrm{g} \mathrm{ml}^{-1}\right)$, producing short chains of cells; $(c)$ vancomycin $\left(100 \mu \mathrm{g} \mathrm{ml}^{-1}\right)$; or $(d)$ vancomycin $\left(100 \mu \mathrm{g} \mathrm{ml}^{-1}\right)$ followed $10 \mathrm{~min}$ later by addition of lysozyme $\left(10 \mu \mathrm{g} \mathrm{m}^{-1}\right)$. Bar, $200 \mu \mathrm{m}$.

chains of cells so formed are shown in Fig. 2. The length measurements presented in Table 1 make it probable that only a few of the poles seen in Fig. $2(b$ and $d)$ have not resulted from the enzymic action, as there is only one chance in 10.4 that a pole had already been formed before the lysozyme treatment. 

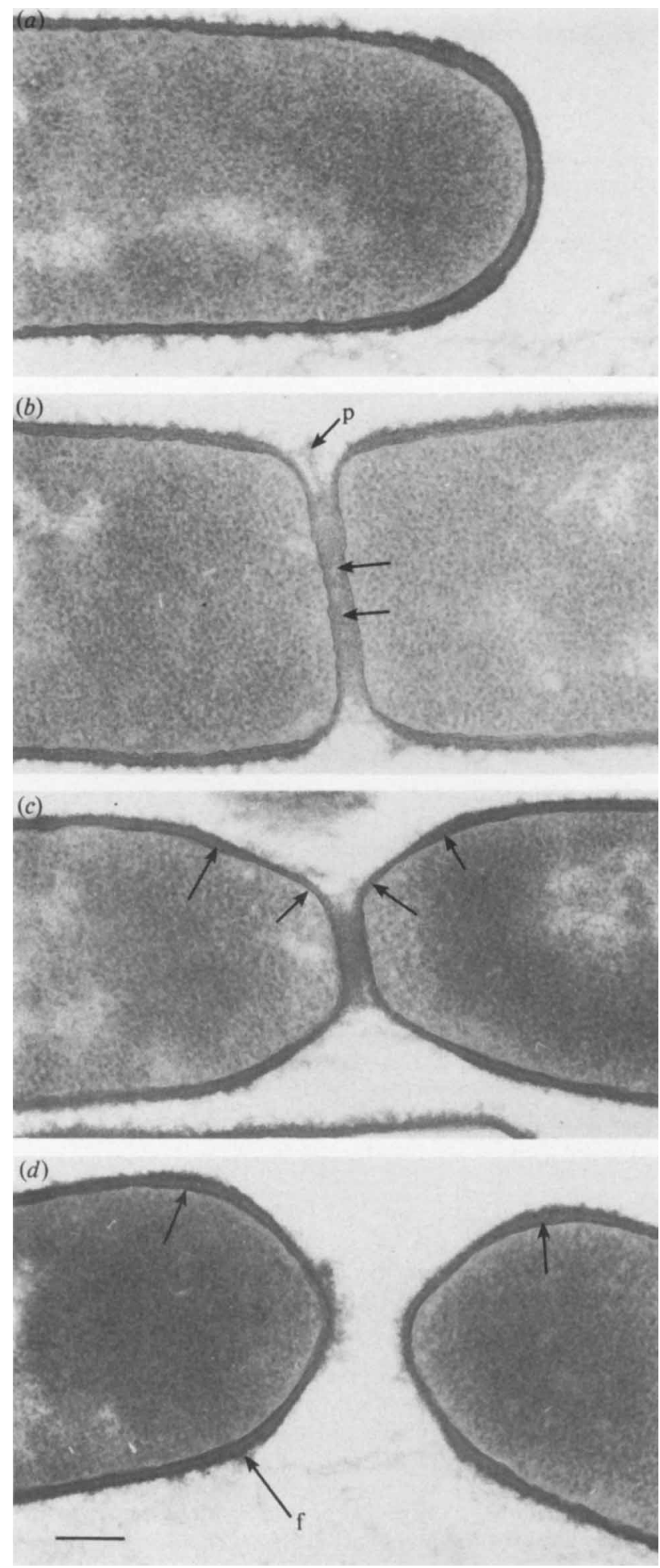
Most of these new poles must have arisen by the splitting of previously completed cross-walls. Not many of the new poles could have been incomplete at the time of lysozyme treatment because completed cross-walls were much more numerous than incipient cross-walls in the growing samples of FJ6 (Table 1). To evaluate the possibility that the new poles were initiated and completed during the $10 \mathrm{~min}$ lysozyme treatment, it was necessary to determine the duration of the pole formation phase of the parental wild-type strain. This time interval could be calculated from the doubling time of the parental strain under the growth conditions used here $\left(t_{2}=30 \mathrm{~min}\right)$ and the proportion of cells showing septation stages during balanced growth $(Y=$ $0.63)$. Substitution of these values into the approximate formula $t_{\mathrm{x}}=[\ln (1+Y)] t_{2} / 0.693$, where 0.693 is $\ln 2$, yielded a value of $21 \mathrm{~min}$ for the time required to form a pole. Therefore, it is unlikely that the lysozyme action initiated de novo formation of normal poles, but that the enzyme instead simply split the existing completed cross-walls.

\section{Pole formation in the presence of vancomycin and lysozyme}

There are many antibiotics that prevent the completion of murein synthesis, but vancomycin acts quickly, by virtue of its binding to the -D-Ala-D-Ala terminus of the pentapeptide (see Rogers et al., 1980). We found that $1 \mu \mathrm{g}$ vancomycin $\mathrm{ml}^{-1}$ was sufficient to stop the turbidity of cultures of FJ6 from increasing. The turbidity was measured on samples that had been well vortexed. Consequently, we repeated the lysozyme experiment with the addition of excess vancomycin $\left(100 \mu \mathrm{g} \mathrm{ml}^{-1}\right)$.

When lysozyme was added 10 min after addition of vancomycin, the mean length of filaments was reduced sixfold compared with the control without vancomycin or lysozyme (see Fig. 2 and Table 1). Vancomycin treatment for $10 \mathrm{~min}$ by itself lowered the mean size of the cell length distribution less than twofold. However, in thin sections, only completed but unseparated crosswalls were observed, of dimensions comparable to that of the control (Table 1).

A simulated sequence of pole construction in the samples exposed to vancomycin and lysozyme is shown in Fig. 3. Separation of the cross-wall, unlike that of B. subtilis $168 / \mathrm{s}$ (Burdett \& Higgins, 1978) or MB21 (data not shown), appeared to occur at two sites adjacent to a central strip of wall (Fig. $3 b$ ). Consequently, a pronounced wedge or plug of septal wall could be seen at early stages of cross-wall severance. The width of the cross-wall $(89 \pm 12 \mathrm{~nm})$ at this stage was slightly greater than that of the control $(79 \pm 12 \mathrm{~nm}$; Table 1$)$. Dissolution of the cross-wall along its length was also evident (Fig. $3 b$ ). In contrast to the parental strain or to B. subtilis 168/s (Burdett \& Higgins, 1978), a pronounced gradient in thickness was visible across the nascent polar surfaces (Fig. $3 c, d$ ). Measurements of wall thickness showed an increase from $23 \pm 2 \mathrm{~nm}$ (adjacent to the separating base of the cross-wall; Fig. $3 c$ ) to $43 \pm 3 \mathrm{~nm}$ (at the junction with the cylindrical wall). Thus, at the widest portion of the polar wall, the thickness was marginally greater than that of the tribanded portion $(36 \pm 4 \mathrm{~nm}$ ) of the peripheral wall. The pole shown in Fig. $3 a$, which bears a rim of wall material and no gradient of thickness, may represent a pole initially present, at the tip of a chain of cells, or possibly the severance of a cross-wall of unusual thickness.

Changes in wall structure, following the addition of lysozyme and/or vancomycin, were confined only to the separation of the cross-walls. The thickness of the peripheral wall including the fringe was $49 \pm 3 \mathrm{~nm}$, which is very similar to that of control cells (Table 1).

\section{DISCUSSION}

The fundamental observation presented here is that the amount of peptidoglycan laid down in the cross-wall of autolysin-deficient mutants is in a sufficiently compact state to be able to

Fig. 3. Electron micrographs of longitudinal sections of $B$. subtilis FJ6 treated for 10 min with vancomycin $\left(100 \mu \mathrm{g} \mathrm{ml}^{-1}\right)$ followed by $10 \mathrm{~min}$ treatment with lysozyme $\left(10 \mu \mathrm{g} \mathrm{ml}^{-1}\right)$. A fully separated pole $(a)$ and a sequence of cross-wall separation $(b-d)$ is shown. Note the central plug (p) of wall material at centre of the cross-wall in $(b)$ and the low density areas (arrowed) suggesting solubilization of cross-walls. A gradient of wall-thickness (arrowed) is present along newly exposed polar surfaces $(c, d)$. A fringe (f) of wall material remains on the cylindrical wall surface. Bar, $0.2 \mu \mathrm{m}$. 
expand to cover the entire surface area of the resultant pole. This would represent an increase of some $52 \%$ in area (Koch \& Burdett, 1986). A second observation is that the combined thickness of the two resultant poles is less than the thickness of the original cross-wall; this is because some of the cross-wall material is cleaved into shreds. The shredded material is attached to a wall whose thickness is comparable, at least in the centre, to the wall thickness of wild-type poles. Therefore, to develop polar walls of the normal thickness the wall must not only be split, but in addition some of it has to be removed. This does not appear to occur in the wild-type strain, and this difference can be used as supportive evidence for the model of wall turnover proposed by Kirchner et al. (1985) and Koch et al. (1985) in which autolysins are inhibited when in proximity to a chemiosmotic membrane that is actively maintaining a protonmotive force. It was noted in many instances that the thickness at the periphery of the pole created with exogenous lysozyme was greater than in normal material. This finding may also be significant in establishing the mechanism that controls the wall thickness. However, this latter finding tends to support our second model, in which the stress patterns in the wall determine the rate of cleavage by autolysins. This follows because the thicker regions near the periphery would support only very little of the stress and so avoid rapid autolysis. These thicker regions may also be the analogue of the wall bands reported earlier (Burdett \& Higgins, 1978).

The fringe of material associated with the side walls of the autolysin-deficient strain was not removed by treatment with lysozyme. This material no doubt consisted of teichoic acid and murein that was no longer serving a structural role for the bacteria, but for lack of sufficient autolytic activity the murein together with teichoic acid chains remained attached to the cell. The teichoic acid is identifiable in other circumstances by binding to ruthenium red or cationized ferritin (I. D. J. Burdett, unpublished). The absence of a changed appearance of the side walls as the new poles were formed by the lysozyme indicates that the cross-wall contained sites that were more labile than those present in the loosely attached fringe. Presumably this is because the poles have come to serve a structural role, and are under tension after the septum splits, whereas the fringe material has been fragmented to the point where it is no longer under stress.

A corollary to the conclusion that no new material is inserted during the cross-wall to pole transition is that mechanistically there is no way that material could be added to the interior part of the wall. Assuming that the penicillin-binding proteins are membrane bound, they could only serve a role in linking nascent peptidoglycan to pre-existing wall and could therefore only function at a distance of no more than $1 \mathrm{~nm}$. This is much less than the $25-30 \mathrm{~nm}$ half-thickness of the cross-wall. Unless there is a functional form of the enzyme that is not attached to the membrane and that has hitherto escaped detection, the wall density must decrease during the transformation from septum to pole.

This work was made possible by a travel grant provided by the Wellcome Foundation. Work in the laboratory of A.L.K. was supported by the Public Health Service under Grant GM 34222.

\section{REFERENCES}

BurdetT, I. D. J. (1980). Quantitative studies of rodcoccus morphogenesis in a temperature-sensitive Rod' $^{-}$mutant of Bacillus subtilis. Journal of General Microbiology 121, 93-103.

BurdetT, I. D. J. \& Higgins, M. L. (1978). Studies of pole assembly in Bacillus subtilis by computer reconstruction of septal growth zones seen in central, longitudinal, thin sections of cells. Journal of Bacteriology 133, 959-971.

BURDeTT, I. D. J. \& КоCH, A. L. (1984). Shape of nascent and completed poles of Bacillus subtilis. Journal of General Microbiology 130, 17111722.

Fein, J. E. \& Rogers, H. J. (1976). Autolytic enzymedeficient mutants of Bacillus subtilis 168. Journal of Bacteriology 127, 1427-1442.
Kirchner, G., KoCh, A. L. \& Doyle, R. J. (1984). Energised membrane regulates cell pole formation in Bacillus subtilis. FEMS Microbiology Letters 24, 143147.

KocH, A. L. (1983). The surface stress theory of microbial shapes. Advances in Microbial Physiology 24, 301-366.

KoCH, A. L. (1984). How bacteria get their shape: the surface stress theory. Comments on Molecular and Cellular Biophysics 2, 179-196.

КоCH, A. L. (1985). Bacterial wall growth and division or life without actin. Trends in Biochemical Sciences 10, 11-14.

KoCH, A. L. \& BURDETT, I. D. J. (1986). Biophysics of pole formation of Gram-positive rods. Journal of General Microbiology 132, 3451-3457. 
KOCH, A. L., KIRCHNER, G., DOYLE, R. J. \& BURDETT, I. D. J. (1985). How does a Bacillus split its septum right down the middle? Annales de Microbiologie 136A, 91-98.

MILLER, J. H. (1972). Experiments in Molecular Genetics. Cold Spring Harbor, NY: Cold Spring Harbor Laboratory.

ROGERS, H. J.(1979). The function of bacterial autoly- sins. In Microbial Polysaccharides and Polysaccharases, pp. 237-268. Edited by R. C. W. Berkeley, G. W. Gooday \& D. C. Ellwood. London: Academic Press.

Rogers, H. J., Perkins, H. R. \& Ward, J. B. (1980). Microbial Walls and Membranes. London: Chapman \& Hall. 